\title{
The Role of Rhetoric: It's Effectiveness in Propagating Persuasion within a Particularized Socio-Cultural Dispensation
}

\author{
YakoboMutiti \\ Rocha Chimera \\ Sarah Mwendar Wallace \\ Pwani University, P.O.Box 195-80108, Kilifi County, Kenya \\ Department of Languages, Linguistics and Literature \\ School of Humanities and Social Sciences \\ Pwani University Kenya
}

\begin{abstract}
Short story writing is recognised as a distinct literary form. Where some stories may teach moral lessons or produce dramatic events, there are those that merely depict events in ordinary life. The movement of classicism in the Western world was a philosophy of art and life that emphasized order, balance and simplicity. Rhetoric is the literary invention of Classicism. This study posits that rhetoric has an undeniable role in short story writing, one that hasn't been adequately interrogated particularly when it emanates from contemporary individual endeavour; a role whereby an effective rhetorical reader can analyse how a text works to fit itself into a context; and can judge how well it accomplishes its task there, by careful examination of the impact of the emotive component applied.
\end{abstract}

Key words: rhetoric, rhetorical tools, rhetorical devices, narrative, persuasion

\section{Introductory Background}

Expressing opinion about the myriad quotidian idiosyncrasies that surround mankind is the sole preserve of creative writers. Their persuasive acumen is what decides the degree to which persuasion can influence the mind of the reader. This study examines the power of rhetorical tools and devices in bringing persuasion to the fore. It manifests as an exercise in the classification of human behaviour by incorporating social theories that attest to these behaviours and do so in rather explicit terms. The social theories are communicational, structural, cognitive, interactionist, interpretive and critical.

\section{Theoretical Background}

Social communicational theories need to be understood as they are inevitably incorporated in creative writing, particularly in short story writing. Among the many social theories that can be observed as being incorporated within the human behaviour that creative writers enjoy to portray, the cognitive dissonance theory highlights dissonance (incompatible beliefs and actions) as being aversive, where the interlocutors are highly motivated to avoid it (McLeod, 2008). Coordinated Management of Meaning (CMM) is a theory that focuses on the relationship between an individual and his or her society (Pearce, 1994). Then there's the theory of Dramatism which compares life to a drama. As in dramatic action, life requires an actor, a scene, an act, some means for the action to take place and a purpose. A rhetorical critic can understand a speaker's motives by analysing these elements (Pearce, 1994). The Social Exchange theory posits that the major force in interpersonal relationships is the satisfaction of both peoples' self-interest; which is not necessarily a bad thing (Homans, 1961). Meanwhile Social Penetration theorists believe that self-disclosure is the primary way that superficial relationships progress towards more intimate relationships; it can also leave one or more persons vulnerable (Altman and Taylor 1973). The Communicational theory of symbolic interaction posits that language allows people to develop a sense of self and to interact with others in the community (Stryker, 1990). The Uncertainty Reduction theory suggests that when strangers meet, their primary focus is on reducing their levels of uncertainty in the situation (Griffin, 2012). As a preamble to the various considerations in creative writing, an understanding of the interplay between these and many other social theories is indispensable. 


\section{Methodological Approach}

This study explored the social and communicational theories and demonstrated the art of persuasion by liberal use of rhetorical tools since rhetoric was the selected theory of reference; tools that can loosely be described as the "what" which is used by the writer to describe an image or bring about a descriptive occurrence. The general population was determined as readers of creative writing in English.

This article focuses on the pilot study which was put in place in order to determine the mode and scope of the research questions that would elicit sentiment on the part of the reader. The instrument chosen by the researcher was a questionnaire, aptly divided into two parts. Part one consisted of personal questions about gender, age, profession and economic disposition. This was considered necessary for the reasons of diversity within the readership. The Story $O f$ Bus Rides and Bottles Of Water was read by six participants (see annex); its annotations reflect the rhetorical tools and devices in question.

Therefore the storyline made use of the following tools of rhetoric among others:

- Foreshadowing: ... an extra VIP chair was awkwardly across the aisle in the first class section - and for this particular journey it was unoccupied!....; such a tool prepares the reader for something to come, normally something that is foreboding

- Concrete language: ...the smell...of burning firewood...; this tool helps the description attain a more graphic level

- Symbolic imagery: ...then it was some kind of claw that caught my hair....; the symbolism being that this claw doesn't augur well for the hapless perpetrator of discomfort to the other person

- Hyperbole: ...only to see a middle-aged man ... apologetically crumple into the VIP seat across the aisle...; the use of the word crumple is the hyperbole, the exaggeration that allows the reader to imagine the character

- Satire: ... your book- like English...; this is a tool that implies mockery

- Sarcasm: ...spoken loud enough to inform the entire bus ... your correspondent was calling from very far away...; this is a tool that plays the role of comic relief here

- Facetiae:...that you were a struggling teacher ...; a tool that introduces mockery

- Analogy: ...I couldn't give you a piece of my mind....; a tool that is emphatic

- Cacophonic personification: ... a face-off between middle-aged, traditional, poverty-stricken, semi-idiocy and notso-young, well-educated, financially stable, narcissistic bigotry....; a tool whose main purpose is being descriptive

- Caustic brevitas:okay, here....; in this case the tool was used for emphasis

- Causal analysis: ... Why did you ask me for a bottle of water? Was it because you knew that I'd been given a free one like you and everyone else? Did that give you a right to ask it of me?...; a tool that plays a thought-provoking role

- Erotema: ... Why did you have to do this to me?...; the proverbial rhetorical question that requires no answer

- Metaphorical innuendo: ... as the object of my displeasure ...; the metaphor being objectivizing the man

- Euphemism (for making things worse than they already are): ...you proceeded to add insult to injury...; this is a very powerful rhetorical tool for any writer in creative writing

- Personification: ...the pretension rearing up its ugly head...; another powerful rhetorical tool normally used for emphasis

- Irony: ...Luckily for you my good upbringing wouldn't allow me to stand up and choke you as you gobbled up what should have been my bottle of water to drink on the journey...; The irony here is that the action of wanting to choke someone else is not normally associated with people who are well brought up. This is a powerful almost inevitable tool to use in creative writing.

The storyline also made use of numerous rhetorical devices of which only those that were impactful can be mentioned here. Rhetorical devices can loosely be described as the "how" which is used by the writer to influence or bias the reader as they read about a descriptive occurrence. Therefore among others, there was the use of:

- Asyndeton (where short clauses follow each other successively): ...(the seat) went unoccupied for half an hour, one hour, one and a half hours, two hours...; this is a device that encourages rapidity in the reading

- Epanalepsis: ... you just couldn't understand their reasoning... you just couldn't...; this rhetorical device where a clause begins and ends with the same words serves to be emphatic about something

- Aposiopesis: ... and now one and a half hours - no two hours - later, you decided...; this device is an abrupt stop in the middle of a sentence, used by a speaker / writer to convey unwillingness or inability to complete a thought or statement

- Ethopoeia: ....so you took control...; ethopoeia is the act of putting oneself into the character of another in order to convey that person's feelings and thoughts more vividly

- Ecphonesis:...Ouch!...; this device is recognized when a sentence consisting of a single word or short phrase ends with an exclamation point. It's a device that serves to bring about dramatism 
- $\quad$ Epanaphora: ...I knew at once that you were rather older than me; that your background and mine were literally worlds apart...; in rhetorical analysis, epanaphora is repeating the same word or phrase for the purpose of emphasis. Therefore its effect on the reader or listener is sublime and not always obvious.

- Onomatopoeia: ...the look I gave you was one of anger for clawing my hair...; this is a device that is always used for emphasis

- Anaphora:...you shifted to the right of the large seat, then to the left, then back to the middle again...; this device hastens the pace of the descriptive mode

- Paramoiosis:....you said something incoherent and mumbled apologetically about a bottle...that bottle... $\underline{\text { bottle of }}$ water...; this rhetorical device means parallelism of sound between the words of two clauses (in this case three in actual fact) that are approximately equal in size. The similarity of sound can occur at the beginning of the clauses, at the end (where it is equivalent to homoioteleuton), in the middle or throughout the clauses. It's a device that implies continuity of thought and slows down the pace of reading, particularly in this case.

- Meiosis (also known as tapinosis): ....where you stupidly managed to stutter...; this is a device where the language or epithet utilized is downright debasing.

- Apostrophe: ...it was a 'silenced transmission of pressurized good breeding' (Wole Soyinka: Telephone Conversation)...; this rhetorical device is a figure of speech consisting of a sudden turn in a text towards an exclamatory address to an imaginary person or a thing. Its role is principally to create and/or sustain interest.

- Non sequitur: ...I fell into a deep unnatural sleep - and suffered an inexplicable nightmare under all that piped music...; this is a device where the statement bears no relationship to the preceding text (which in this case was selfish remorse)

The tools and devices mentioned here are only 25 of the 60 that were liberally employed within the storyline (see appendix).Therefore, an exploratory and descriptive research design was adopted whereby final and conclusive answers to the research questions were generally interpreted by the researcher. The study was carried out in Kilifi Kenya and Jersey Island UK. The general population considered was: readers of creative writing in the English language. The instrument utilized for data collection was a two-part questionnaire distributed between six units that were representative of the readership and stratified between male and female. A story was distributed within the readership, replete with rhetorical tools and devices whose sole intention was to become persuasive. Analyses of the responses were mainly by contextual inference.

\section{Data: Results of the Pilot Study and interpretive discussion}

A story titled Of Bus Rides and Bottles of Water was read (Wallace, 2017). A questionnaire was then distributed with multiple choice questions for the purposes of expediency. As has been mentioned before, Part 1 comprised of questions of a personal nature in order to bring out the diversity of the readership. Therefore the general information in Part 1 was indicative of the researcher's desire to have the widest spectrum possible of age disparity between the two genders, varied levels of literacy, different professions and an appreciation of the economic disposition of the readers of the story.

Part 2 of the study comprised of the reaction of the readership to the story. The general population was: readers of creative writing in the English language. The units comprised of six participants, three male and three female. This number sufficed for the intended first objective of the main research study: to demonstrate the uses of rhetoric in socially diverse contexts, in an effort to persuade the reader.

Question 1.Interrogation about the appropriateness of the title to the story: How appropriate was the title of the story to the story?

Where one male participant found the title very appropriate, two found it inappropriate. Within the female cohort, two female participants were of the view that the title was indeed appropriate; whereas only one of them found it inappropriate. This was a graphic story. The rhetorical tools and devices that have already been mentioned as having been used among many others could have enhanced the correlation between the storyline and its title, or they could have obscured it. What transpired is that the female participants appear to be more receptive to the appropriateness of the title to the story than the male participants. This was also interrogation about logical considerations. Because two of the three female participants found it appropriate, the researcher infers that females who read creative writing such as this story that affects them sentimentally, are quick to accept the correlation between title and content; whereas males who are more driven towards argumentation, may hesitate and prefer the option of 'inappropriate' in a subconscious endeavour to seek to differ.

Question 2. Interrogation about the story's effect upon the reader: How has the story affected you now that you've read it? One male participant felt sad and opted precisely for this epithet. The other two were both surprised by the entire storyline. 
Within the female cohort, only one female participant was surprised while the other two were both disgusted by the progression of the storyline. The epithets were varied: happy, sad, shocked, surprised, indifferent, disgusted, and noneof-the-above. That the rest of the spectrum of choices was ignored with the exception of the two above-mentioned was particularly instructive to the researcher: half the participants were surprised.

Between the two genders the majority of the male participants were surprised by the story and by the writer, a rather reserved position to take in comparison to their female counterparts according to the researcher. The more powerful sentiment of disgust by a majority of the female participants, starkly points to the emotive nature of females in the real world, which is then sustained within artistic creativity. This was concurrently an ethical interrogation since it pointed towards the intentions of the writer towards her readers. Therefore ethically speaking this storyline did not endear the female readers to the creative writer whereas the male readers did not appear to have expected such an ending.

Question 3. Interrogation about the language of the writer: How was the language used by the writer?

Language is viewed as instrumental to how the writer achieves her purpose for telling the story (Trudgill, 1974) particularly when emotive issues are being described(pathetic appeal). The entire readership both male and female overwhelmingly chose to describe the language used as being strong. The researcher infers this to mean that the story was particularly graphic. Therefore what was intended was achieved. Vague, threatening, don't know, were the other choices on offer; that none of them was opted for points to the dogmatic nature of both males and females whenever they have strong convictions to express.

Question 4. A multi-faceted interrogation since it was both logical and emotive: What would you say about a writer who could write a story like that?

Two of the male participants called the writer honest; one of them opted to apply all the epithets on offer to the writer, picking 'all of the above' from the list of: selfish, honest, guilty, temperamental, all-of-the-above. Conversely, the female participants unanimously chose: honest. The researcher infers that the overriding perception demonstrated is one of honesty on the part of the writer.

Question 5. Emotive interrogation: Was there an element of surprise in the story?

The options to choose from were only two: 'yes, here and there' or 'no, nowhere' with the rider 'please underline just one answer'. All the participants both male and female unanimously agreed to being surprised by the events that they read within the storyline. What is instructive to the researcher is that this element of surprise is precisely what must have sustained the motivation in reading the story from the beginning to the end.

Question 6. Ethical and logical interrogation: Use one word to describe the story.

Several epithets were on offer: incredible, believable, interesting, uneventful, boring. The participants were required to choose just one answer. Two of the three male and female participants found the story believable. One each of the three male and female participants found the story interesting. The researcher infers these results to be due to a successful employment of the rhetorical tools and devices already mentioned.

\section{Conclusive Discussion}

The narrative voice seems to have achieved its ends in this storyline since it remained interesting to its audience to the point of making the writer believable. This translates to logical argumentation where the actual point being made by the writer was not just understood but also believed by the readership. This pilot study was a precursor to the main study which eventually elicited remarks that were not too dissimilar.The art of persuasion is heavily dependent upon rhetorical tools and devices during the exercise of short story writing. Whereas this article focalised on the outcome of the pilot study, some aspects of the main research study can however be mentioned in brief at this point, where the perspective of the influence of rhetorical tools and devices is being considered. The main research study also had further stratification other than that of males and females; the participants were also classified as native speakers and non-native speakers of the English language.Within the main research study Part 1 revealed the following challenges:

- Who qualifies as a native speaker of the English language: individuals with bi-lingual native language competencies had not been foreseen by the researcher; ultimately only those where English had supplanted the other language were allowed to participate.

- Apparently social class, age and gender were not particularly influential factors in the elicitation of emotive appeal.

- Income levels, class distinction and professionalism turned out to be very closely related and therefore produced similar results.

In Part 2 the various strata produced more distinct results where the general inferences drawn by the researcher were more clear-cut:

- Generally-speaking females are more accepting of an outcome than males 
- Native speakers of English are capable of remaining detached where non-native speakers are deeply influenced by the protagonists and their actions.

- Ethical appeal drew a wide and varied spectrum of epithets which was highly intended by the researcher right from the onset however, the fact that some would turn out to be complete opposites of each other was not entirely foreseen; for instance ominous language is totally different from language that is indistinct.

- Maintaining interest in a storyline has been proved to be paramount to achieving a certain level of persuasion.

- Curiosity is similar to interest and both these sentiments attest to a respectful level of reasoning rather more than to emotive appeal.

- Logical appeal appears to have been more enticing to the male native speakers of English, at a slightly higher percentage than their female counterparts.

- Pathetic appeal was dominant as an overriding perception of the storyline but only among all of the non-native speakers of the English language.

Challenges confronted by the readership within the main research study were accommodated in a separate cover as additional personal commentary that the participants were encouraged to provide. None of the non-native speakers of English offered additional observations. But some of the native speakers were happy to profit from this liberty where:

- $\quad$ Native speaker competency had to be thrashed out during the recruitment of participants

- Answer choices on offer were found to be insubstantial

- Chagrin towards the question about title appropriateness drew opposing responses: where one was in consternation about the question being asked at all ( a female native speaker), another was overjoyed at the parallelism of the logical sequence of events with an incident in real life that had been embellished by literary creativity (a male native speaker)

The results of the research study therefore were that:

- Non-native (or second-language speakers) of English are prone to heavy emotive influence when rhetorical tools and devices are used to persuade them.

- Native speakers of English, irrespective of age and gender are simply not affected in the same way as non-native speakers of English, no matter what rhetorical tools and devices are utilized.

\section{Addendum}

\section{Story: Of Bus Rides And Bottles Of Water}

This was a long-distance bus; so it was spacious and new and luxurious ${ }^{1}$. The tendency was to copy the airline industry and divide the bus into sections. So the front of the bus was the VIP section. The one row behind them was first class and the rest of the chairs behind were economy class. An extra VIP chair was awkwardly across the aisle within the first class section - and for this particular journey it was unoccupied! ${ }^{2}$ It went unoccupied for half an hour, one hour, one and a half hours, two hours ${ }^{3}$...... and you watched it from a rear seat in the economy class....

Ever since the bus began its journey in fact you had been watching that seat. You had been wondering why anyone would pay more money just to be in the same bus with other people, going in the same direction, covering the same distance, and even listening to the same music - breathing the same ${ }^{4}$ air!... Why was it that some people always wanted to be seen as different from others? ${ }^{5}$ You just couldn't understand their reasoning, you just couldn' $t^{6} . .$. . And now, one and a half hours - no two hours - later, you decided .....

The turn-boy arrived at the rear of the bus, amicably and dutifully handing out bottles of mineral water for the travellers to enjoy courtesy of the bus management, as the vehicle proceeded towards the warmer coastal towns. Then he turned to go back to the front of the bus and didn't appear to have noticed the unoccupied VIP seat, as he perfunctorily dropped down ${ }^{8}$ onto the step near the door and opposite the driver, to continue from where he'd left off in some kind of inane conversation....

You decided that you could also enjoy some 'special' treatment on this bus. You'd boldly walk up to that VIP seat and defiantly occupy it whether anyone else liked it or not!'So you took control ${ }^{10}$ and you did just that!

First it was the smell, a smell ${ }^{11}$ of burning firewood ${ }^{12}$; $\operatorname{gross}^{13}$; then it was some kind of claw ${ }^{14}$ that caught my hair as you clutched at the headrest of my first-class seat. Ouch $!^{15}$ Since I had been dozing off, lulled by the rhythm of the bus and the bass guitar from the sounds of piped music, that claw in my hair did not augur well for you. I turned in surprised anger to question the source of my discomfort ${ }^{16}$, only to see a middle-aged man in a mouse-coloured suit apologetically crumple ${ }^{17}$ into the VIP seat across the aisle from me, looking as if he was gasping from the effort of having walked all the way from the back of the bus to accomplish this feat: to sit in this chair, this ${ }^{18}$ one here....then you looked at me sheepishly ${ }^{19}$. 
Of course in that instant your age confused my thinking processes since I knew at once that you were rather older than me; that ${ }^{20}$ your background and mine were literally worlds apart - and I was right! No sooner had you plonked ${ }^{21}$ yourself down than your little ancient mobile phone made a loud rasping, illiterate ${ }^{22}$ noise by way of ringing. Your book-like English $^{23}$, spoken loud enough to inform the entire bus since your correspondent was calling from very far away ${ }^{24}$, informed everyone whether they cared to hear it or not, that you were a struggling teacher ${ }^{25}$ in a primary school upcountry and on your way to a big meeting in the coastal region. The confusion in my mind then was due to my upbringing: traditionally the younger of two people is supposed to show respect to the older one - unconditionally; and especially when she's a woman, which happens to be my gender of birth and choice. So I couldn't give you a piece of my mind ${ }^{26}$, which is the way my education had taught me, was by virtue my God-given right. All I could do was glower at you and keep my mouth tightly closed in an effort to allow my traditional upbringing to hold sway ${ }^{27}$.

Let me reiterate: the look I gave you was one of anger for clawing ${ }^{28} \mathrm{my}$ hair! But you on the other hand must have misunderstood it for something else. After your phone conversation you started to fidget; you shifted to the right of the large seat, then to the left, then ${ }^{29}$ back to the middle again, just like a goose $\mathrm{s}^{30}$ landing on a pond and ruffling its feathers to settle down. Each time you shifted slightly, you threw me a side glance while I for my part, pretended to be asleep while I peered at you from beneath my false long dark eyelashes.....trying to simmer down.

Then you did the most annoying thing of all - you leaned towards me and woke me up!Woke me up!! ${ }^{31}$ You said something incoherent and mumbled apologetically about a bottle...that bottle ....bottle ${ }^{32}$ of water ...the one in your bag...

MY bag?! Were you really asking me for the bottle of water in my bag? A bottle that no-one could see by the way since I had stashed it right inside! My bottle! ${ }^{33}$ (courtesy of the bus company). You had simply assumed that the bottle handed to me by the conductor was stashed away somewhere in my bag - how dare you ask me for my bottle of water how dare you! $!^{34}$ The angst I felt rose up my neck to the bottom of my jaw. I didn't realize it then but this was actually a face-off between middle-aged, traditional, poverty-stricken semi-idiocy and not-so-young, well-educated, financiallystable, narcissistic bigotry ${ }^{35}$ : two complete and absolute opposites.

"There are more bottles of mineral water over there...extra ones...next to the conductor; just go and ask him, he won't refuse" - my voice was forcibly condescending. "No. I want your water...." you stupidly ${ }^{36}$ managed to stutter "the one in your bag....mine is too far away...I mean, I'll give you mine later on to refund you...but for now...can you give me your bottle of water to drink? (no please, almost like a command) Some seconds passed in utter silence. ${ }^{37}$ It was a "silenced transmission of pressurized good breeding" (Wole Soyinka: Telephone Conversation ${ }^{38}$ ). When my voice did come, it was certainly "lip-stick-coated, long gold-rolled cigarette-holder pipped" (same poet, same poem; verbatim). "Okay, here."39

For the first time in my life, I found myself giving without wanting to, offering without ${ }^{40}$ mirth; it was all I could do not to throw it at your desperate insistent face! Why did you ask me for a bottle of water? Was it because you knew that I'd been given a free one like you and everyone else? Did that give you a right to ask it of me? ${ }^{41}$ Even when it was wellhidden in my bag? How dare you? How dare you ${ }^{42}$ bring out the worst in me? In me ${ }^{43}$, a person who is normally generous at heart. You make me feel awful. I loathe the fact that the mere request for a bottle of water to drink can make me so angry to have to give it to you. You ${ }^{44}$ give me no choice. You scorn my advice. You make me feel bad. You make me feel ${ }^{45}$ like standing up and doing something very crude to shock you into consternation...; why did you have to do this to me ${ }^{46}$ Or was it your need to feel equal to me that gave you the impetus to dare to ask me what you knew we both had - what we all had - as if you had every right to it anyway ${ }^{47}$ as a traditional older man; one who was not supposed to be turned down ${ }^{48}$ by a younger woman - whether or not she was 'educated' ${ }^{49}$ Surely not. ${ }^{50}$

I seethed. Seethed ${ }^{51}$. You gobbled ${ }^{52}$ the contents noisily, seemingly unaware of the selfish turmoil in my mind; selfish because as the object of my displeasure ${ }^{53}$ you proceeded to add insult to injury ${ }^{54}$ by deferring to me pretentiously; the pretension rearing up its ugly head ${ }^{55}$ because you gave me no choice and you knew it. You horrible individual. ${ }^{56}$ Luckily for you, my good upbringing wouldn't allow me to stand up and choke you as you gobbled up what should have been my bottle of water to drink on the journey. ${ }^{57}$

The bus came to a halt. Everyone descended for a twenty-minute break for food and refreshments. I assuaged my mixed feelings with some vanilla ice-cream (comfort food) and went back to the bus with a chilled bottle of peach-andpear fruit mix; absolutely delicious. Then you lumbered ${ }^{58}$ up to my chair with a warm bottle of mineral water clutched in your big claws and half-heartedly offered it to me as a form of refund, careful this time not to get too near my head. I declined.

And you....you ${ }^{59}$ promptly pulled off the cap, stuck the bottle up between your big, thick, lips and proceeded to empty the contents; as if my refusal was precisely what you had expected and rightly so. 
I fell into a deep unnatural sleep - and suffered an inexplicable nightmare under all that piped music. ${ }^{60} \mathrm{~A}$ 'wanna-be' VIP and a first-class passenger, both on the same journey, so alike and yet so different; each reminiscent of the paradox of egocentrism - and lack of it.

\section{Acknowledgements}

Prof.YakoboMutiti for technical assistance

Prof. Rocha Chimerah also for technical assistance

Dr. Nancy Ngoa COD for general support

\section{References and Bibliography}

Baldwin, CS 1924. Ancient Rhetoric and Poetic.Macmillan Bloomfield, L 1933. Language.New York: Henry Holt and Company

Bourdieu, P 1982. Ce Que Parler Veut Dire: L'ÉEconomie des ÉEchangesLinguisiques.Fayard

Calvet, L-J 1993. La Sociolinguistique, PUF, «Que sais-je? »Ëd. du Seuil

Chappell,VA., Gillam, AM 2002. Instructor's Manual, Reading Rhetorically.Pearson Education USA

Eisenhart, C and Johnstone, B 2008.Rhetoric in Detail: Discourse Analyses of Rhetorical Talk and Text. John Benjamins

Fasold, R 1990. The Sociolinguistics of Language.Basil Blackwell Ltd. USA

Fishman, J 1971. Sociolinguistique.Nathan, France

Hymes, D 1964.Language in Culture and Society.New York

Jacobson, R 1963. Essais de Linguistique Générale. Ed. du Seuil

Labov, W 1972. Sociolinguistic Patterns. University of Pennsylvania Press

Milics, D 2007.A New Handbook of Literary Terms. Yale University Press

Sheridan, T. 1781. A Rhetorical grammar of the English Language (facsimile edition, 1969). Scholar Press

Steinberg, S 2006.Persuasive Communication Skills.Juta and Company

Trudgill, P 1974. Sociolinguistics: An Introduction. Penguin Books

Wallace, S 2017.The Art of Persuasion: Using Rhetorical Means to Discuss Speech, Poetry and Prose.EI Ltd., Nairobi, Kenya.

Yule, G.1995. The Study of Language.Cambridge University Press, UK

Zarefsky, D 2001.Encyclopedia of Rhetoric.Oxford University Press.

http://www.peoi.org/Courses/Coursesen/mass/mass2.htm(Altman \& Taylor, 1973; Victorri\& Fuchs, 1996 \& 2000Social Penetration Theory; Griffin, 2009 Standpoint Theory; Griffin, 2012 Uncertainty Reduction Theory; Klein 2009 Groupthink; Giddens, 1984 Structuration Theory; Stryker, 1990 Symbolic Interaction Theory; Homans, 1961 Social Exchange Theory; Pearce 1994 Coordinated Management of Meaning (CMM); Dumova\&Fiordo, 2010 Communication Accommodation Theory; McLeod 2008 Cognitive Dissonance Theory; Brown \& Levinson, 1978 Face Negotiation Theory; Bissell et al 2001 Anonymous)

\section{WARRANTY}

- This research study is my own original work

- I have rights in the work

- This work is submitted for first publication in the journal

- It is not being considered for publication elsewhere

- It has not already been published elsewhere

- I have obtained and can supply all necessary permissions for the reproduction of any copyright works not owned by me 